\title{
$O$ conhecimento dos profissionais de enfermagem frente à parada cardiorrespiratória na emergência
}

The knowledge of nursing professionals regarding cardiorespiratory arrest in emergency

El conocimiento de los profesionales de enfermería sobre sobre la detención cardiorrespiratoria en emergencia

Isabela Sant'Anna de Farias ORCID: https://orcid.org/0000-0003-2933-4947

Universidade Estácio de Sá, Brasil

E-mail: isabela.2000@hotmail.com

Leticia Velozo Domingos Pinto

ORCID: https://orcid.org/0000-0002-1133-9427

Universidade Tuiuti do Paraná, Brasi

E-mail: leticiavelozo99@gmail.com

Raquel dos Santos da Costa

ORCID: https://orcid.org/0000-0001-9765-7452

Universidade Estácio de Sá, Brasil

E-mail: raquelcosta200700@gmail.com

Tamíris Alves Chagas

ORCID: https://orcid.org/0000-0001-6236-1117

Centro Universitário UNIFACISA, Brasil

E-mail: alvestamiris2207@gmail.com

Júlia Lião Serra

ORCID: https://orcid.org/0000-0001-7409-0000

Universidade Estácio de Sá, Brasil

E-mail: julialserra.enfermagem@gmail.com

Maria Eduarda Cardoso Rabelo de Souza

ORCID: https://orcid.org/0000-0002-7048-0893

Universidade Estácio de Sá, Brasil

E-mail: maria.estacioenfe@gmail.com

Raiane Lopes Araujo

ORCID: https://orcid.org/0000-0001-9474-8658

Centro Universitário Maurício de Nassau, Brasil

E-mail: rayannearaujo2022@gmail.com

Rebeca da Silva Araújo

ORCID: https://orcid.org/0000-0003-2932-2399

Universidade Estadual de Feira de Santana, Brasil

E-mail: rebecas.araujo@hotmail.com

Allan Bruno Alves de Sousa Santos

ORCID: https://orcid.org/0000-0001-6412-7164

Faculdade de Educação São Francisco, Brasil

E-mail: abass@faesf.com.br

Jessica Cristina Lins Zandim

ORCID: https://orcid.org/0000-0002.5408.9800

Universidade Estácio de Sá, Brasil

E-mail: jhessykhrystynna@gmail.com

Mariana de Jesus Meira

ORCID: https://orcid.org/0000-0002-9593-6674

Centro Universitário FG, Brasil

E-mail: mariana-meira12@hotmail.com

Rafaela de Jesus Portugal

ORCID: https://orcid.org/0000-0002-7895-9372

Universidade Salvador UNIFACS, Brasil

E-mail: rafaelaenfermagem2@gmail.com

Leandro Barbosa Teixeira

ORCID: https://orcid.org/0000-0002-9444-7828

Universidade Estácio de Sá, Brasil

E-mail: lbtteixeira@hotmail.com 


\begin{abstract}
Resumo
Objetivo: Discorrer sobre a importância dos conhecimentos dos profissionais de enfermagem frente a uma situação de parada cardiorrespiratória na emergência. Metodologia: Trata-se de uma revisão integrativa de literatura, realizada nas base de dados da Biblioteca Virtual em Saúde, utilizando os descritores "Conhecimento", "Enfermagem", "Enfermagem em Emergência", "Emergência" e "Parada Cardíaca" combinados entre si através dos operadores booleanos "AND" e "OR", abrangendo estudos publicados nos últimos 5 anos (2016-2021), disponíveis na íntegra e que respondessem a questão norteadora: Como o conhecimento dos profissionais de Enfermagem implica na sua atuação frente à parada cardiorrespiratória na Emergência? Resultados: A partir dos critérios de inclusão e exclusão, obteve-se uma amostra final de 18 artigos dos quais $21,6 \%$ correspondem a artigos do tipo estudo descritivos, tendo predominância estudos publicados no ano de 2017. Conclusão: Percebe-se então que as atualizações constantes para os estes profissionais são importantes contribuindo no reconhecimento dos principais sinais e sintomas de uma PCR, realizando intervenções necessárias e manobras qualificadas sem interferir na saúde do paciente. Estes tipos de atualizações podem ocorrer através de projetos de educação permanente visando o desenvolvimento, autonomia e valorização dos enfermeiros.
\end{abstract}

Palavras-chave: Conhecimento; Enfermagem; Enfermagem em emergência; Emergência; Parada cardíaca.

\begin{abstract}
Objective: Discuss the importance of knowledge of nursing professionals facing a situation of cardiac arrest in the emergency department. Methods: This is an integrative literature review, carried out in the Virtual Health Library database, using the descriptors "Knowledge", "Nursing", "Emergency Nursing", "Emergency" and "Heart Arrest" combined with each other through of the Boolean operators "AND" and "OR", covering studies published in the last 5 years (2016-2021), available in full and that answered the guiding question: How the knowledge of nursing professionals implies in their performance in relation to cardiopulmonary arrest in Emergency? Results: Based on the inclusion and exclusion criteria, a final sample of 18 articles was obtained, of which $21.6 \%$ corresponding to descriptive study articles, with a predominance of studies published in 2017. Conclusion: It is noticed that constant updates for these professionals are important, contributing to the recognition of the main signs and symptoms of a CPA, performing necessary interventions and qualified maneuvers without interfering with the patient's health. These types of updates can occur through ongoing education projects aimed at the development, autonomy and appreciation of nurses.
\end{abstract}

Keywords: Knowledge; Nursing; Emergency nursing; Emergency; Cardiac arrest.

\begin{abstract}
Resumen
Objetivo: Discutir la importancia del conocimiento de los profesionales de enfermería ante una situación de paro cardíaco en urgencia. Metodología: Se trata de una revisión integradora de la literatura, realizada en la base de datos de la Biblioteca Virtual en Salud, utilizando los descriptores "Conocimiento", "Enfermería", "Enfermería de Emergencia", "Emergencia" y "Paro Cardiaco" combinados entre ellos a través de los operadores booleanos " Y "y" O ", que abarcan estudios publicados en los últimos 5 años (2016-2021), disponibles en su totalidad y que respondieron a la pregunta orientadora: ¿Cómo implica el conocimiento de los profesionales de enfermería en su desempeño ante la parada cardiopulmonar en el ¿Emergencia? Resultados: A partir de los criterios de inclusión y exclusión se obtuvo una muestra final de 18 artículos, de los cuales el 21,6\% corresponden a artículos de estudio descriptivo, con predominio de estudios publicados en 2017. Conclusión: Se percibe entonces que la actualización constante de estos profesionales es importante contribuyendo al reconocimiento de los principales signos y síntomas de un CPA, realizando las intervenciones necesarias y maniobras calificadas sin interferir con la salud del paciente. Este tipo de actualizaciones pueden ocurrir a través de proyectos de educación continua orientados al desarrollo, la autonomía y la valoración del enfermero.
\end{abstract}

Palabras clave: Conocimiento; Enfermería; Enfermería de emergencia; Emergencia; Paro cardíaco.

\title{
1. Introdução
}

A parada cardiorrespiratória (PCR) é definida como a cessação súbita dos batimentos cardíacos e a ausência de pulsação e respiração, além disso encontra-se associada a presença de quatro ritmos cardíacos: assistolia, atividade elétrica sem pulso, fibrilação ventricular e taquicardia ventricular sem pulso, sendo que os dois últimos ritmos necessitam do uso de um desfibrilador (Brandão et al., 2020).

A PCR visa ser uma das principais emergências acometidas, nela, o paciente se encontra com as atividades circulatórias e respiratórias interrompidas. Os profissionais da área da saúde tendem-se ter um olhar mais direcionado, com isso, contamos com o monitoramento do Suporte Básico de Vida (SBV) e o Suporte Avançado de vida (SAV) no qual são de 
extrema importância para a avaliação do paciente, realizando o chamado ao serviço de emergência, suporte ventilatório de compressões torácicas a cerca que o paciente retorne a sua consciência (Medeiros et al., 2021).

O SBV é fundamental para o atendimento primário de reanimação em casos de PCR, incluindo reconhecimento imediato do agravo, ativação do serviço de emergência, realização de ressuscitação cardiopulmonar (RCP) imediata de alta qualidade e acesso rápido ao desfibrilador (Brandão et al.,2020). O SAV deve ser realizado no ambiente intra-hospitalar, pois requer maior habilidade e conhecimento, envolvendo a RCP de alta qualidade, a desfibrilação, dispositivos de vias aéreas avançadas e oxigênio, acesso venoso e drogas, dispositivos de compressão mecânica e dispositivos de oxigenação por membrana extracorpórea (Velasco et al., 2019).

Neste contexto, é necessário que os profissionais de saúde estejam aptos para identificar uma PCR e iniciar de maneira imediata a RCP, a qual consiste em uma sequência de manobras e procedimentos voltados à circulação cerebral e cardíaca, e consequentemente a sobrevida do paciente. As taxas de sobrevivência e resultados de pacientes após PCR estão diretamente ligadas à rapidez com que a RCP é iniciada e a qualidade de sua realização. A rápida intervenção na PCR de forma segura, eficaz e de alta qualidade pode dobrar ou triplicar a sobrevida. A cada minuto reduz a chance de sobrevivência da vítima em cerca de 7\% a 10\% (Brandão et al., 2020).

Assim, tem-se na educação permanente - forma de educação continuada dia após dia - uma forma importante para atualização do conhecimento dos profissionais de Enfermagem sendo, portanto, uma ferramenta indispensável nas unidades de saúde (Guskuma et al., 2019).

Além da educação permanente, a equipe de saúde pode buscar se atualizar através da leitura e do uso dos Guidelines publicados e atualizados a cada 5 anos pela AHA (American Heart Association), os quais contribuem na otimização dos procedimentos (Barbosa et al., 2018).

Ter uma equipe capacitada faz toda diferença durante a assistência, o enfermeiro como supervisor pode utilizar do processo de ensino-aprendizagem para qualificar sua equipe usando a educação permanente, uma excelente ferramenta para a atualização do conhecimento desses profissionais (Guskuma et al., 2019). A capacitação dos profissionais de Enfermagem é um processo de aprendizado dinâmico e baseado em evidências e respostas aos questionamentos, assim, surge à qualificação profissional (Brandão et al.,2020).

É notório que profissionais enfermeiros que desempenham melhores conhecimentos sobre o assunto são aqueles que participaram de cursos de atualização no último ano, dessa forma, se mantendo atualizado e preparado para as possíveis vítimas de PCR que possam vir a ser acometidas. A maior dificuldade está presente nos cuidados pós-parada cardiorrespiratória, tendo assim, a necessidade de ampliar as atividades de educação permanente, a fim de qualificar a assistência prestada (Lisboa et al.,2016).

Têm-se que a maioria dos profissionais especializados na área, possuem o conhecimento para identificar uma PCR, buscando assim, aperfeiçoamento sobre o tema e buscando novas atualizações. Sendo de grande importância o conhecimento dos profissionais enfermeiros nesta área, pois sua competência é um fator crítico na determinação do sucesso da assistência e fundamentação da ação executada, com características determinantes e condicionantes que contribuem para a sobrevivência inicial de uma vítima em PCR (Barros \& Luis Neto, 2018).

\section{Metodologia}

Trata-se de uma revisão integrativa de literatura, a qual consiste em um método utilizado para sistematização dos resultados encontrados em artigos publicados em bases de dados de forma ordenada, sistemática e abrangente (Ramalho Neto et al., 2016; Ercole et al., 2014). 
Com o intuito de melhor nortear a busca na literatura, estabeleceu-se a seguinte questão norteadora: Como o conhecimento dos profissionais de Enfermagem implica na sua atuação frente à parada cardiorrespiratória na Emergência? A qual foi elaborada através da estratégia PICo, uma ferramenta utilizada para auxiliar na elaboração da pergunta da pesquisa (Santos \& Galvão, 2014), conforme descreve o Quadro 1.

Quadro 1: Estratégia PICo.

\begin{tabular}{|l|l|}
\hline \multicolumn{2}{|c|}{ Estratégia PICo } \\
\hline P (Pessoa/Paciente) & Profissional de Enfermagem \\
\hline I (Interesse) & Conhecimento \\
\hline Co (Contexto) & Parada Cardiorrespiratória \\
\hline
\end{tabular}

Fonte: Autores (2021).

A busca dos artigos ocorreu no período de agosto a setembro de 2021, por meio da base de dados BVS (Biblioteca Virtual em Saúde). Para que fossem encontrados artigos que abordassem a temática, buscou-se selecionar estudos através dos Descritores em Ciências da Saúde (DeCs): "Conhecimento", "Enfermagem”, "Enfermagem em Emergência”, "Emergência”, e "Parada Cardíaca", combinados entre si através dos operadores "AND" e "OR". A pesquisa da literatura se deu em 04 fases: Identificação, Exclusão, Elegibilidade e Inclusão, as quais são exemplificadas na Figura 1.

Figura 1: Fluxograma de informação com as diferentes fases de uma revisão integrativa.

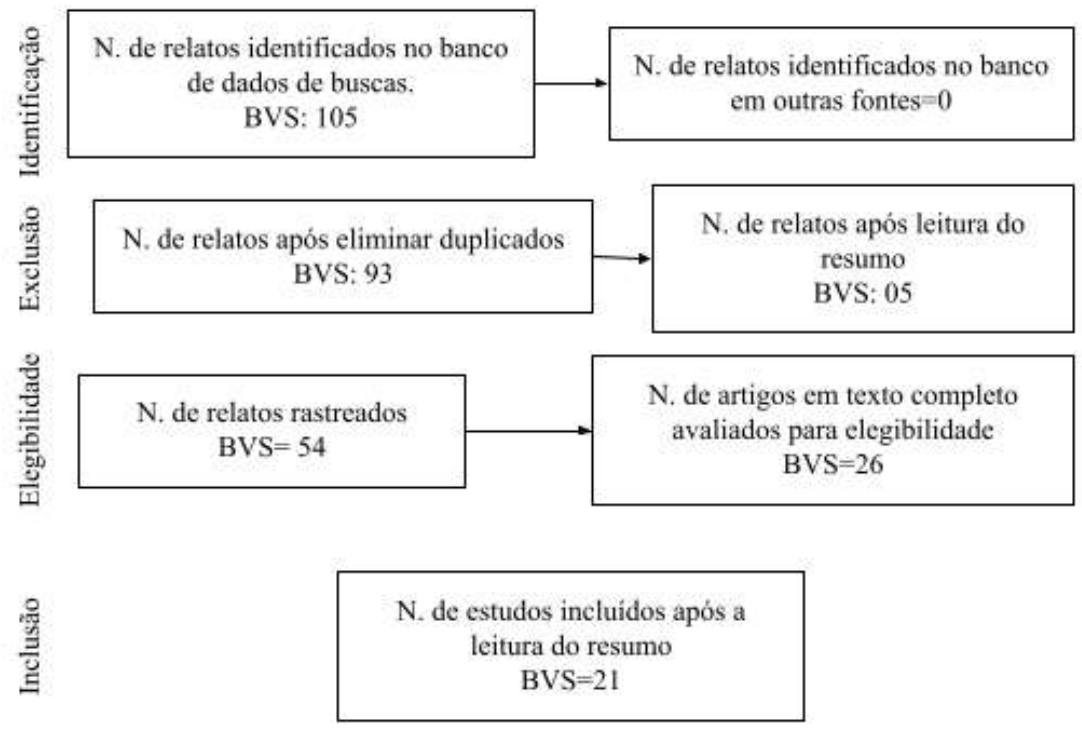

Fonte: Autores (2021).

Elegeu-se como critérios de inclusão: artigos nos idiomas português e inglês que respondiam à questão norteadora, completos e publicados nos anos de 2016 a 2021. Foram excluídas pesquisas em outras línguas, incompletas, duplicadas e que estavam fora do recorte temporal. Inicialmente foram selecionados 105 artigos, que após leitura dos títulos, resumos e adoção dos critérios de inclusão e exclusão, restaram 21 estudos para leitura na íntegra conforme a Figura 2. 
Figura 2: Fluxograma de pesquisa com os descritores.

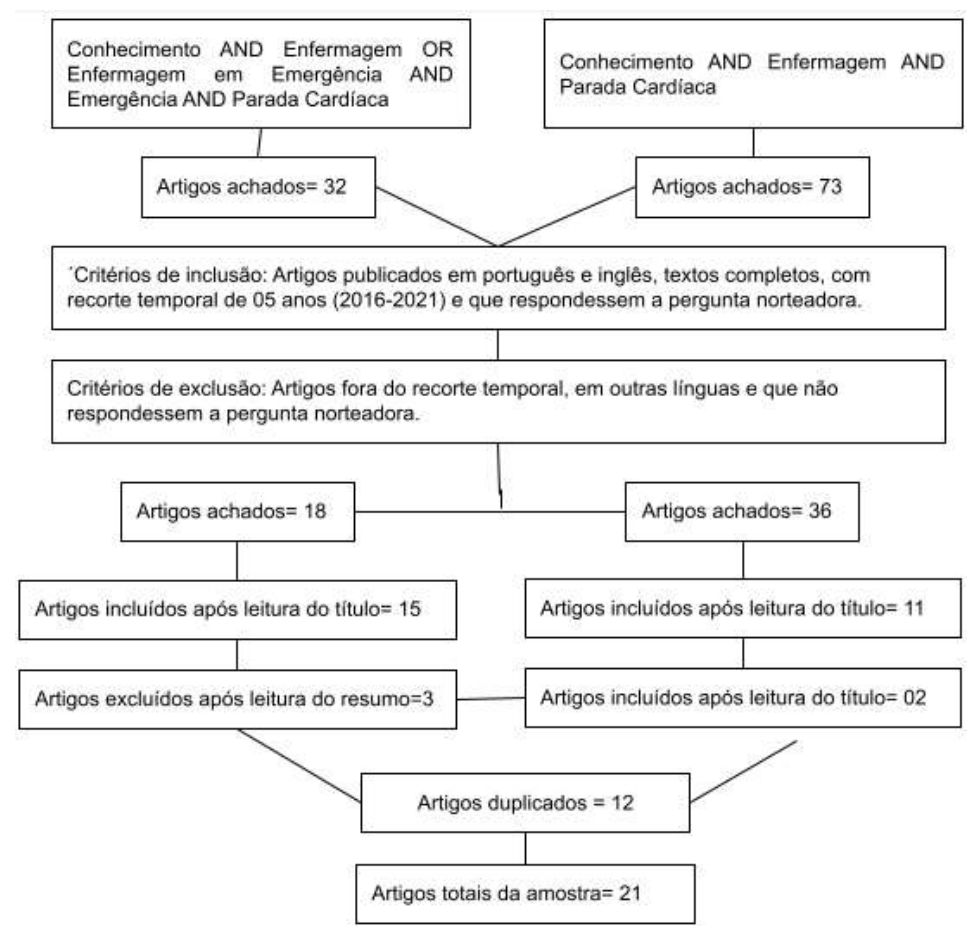

Fonte: Autores (2021).

Após leitura, os artigos foram categorizados e analisados.

\section{Resultados e Discussão}

Foram incluídos na pesquisa, um total de 21 artigos, os quais estão descritos no Quadro 2.

Quadro 2: Estudos selecionados ( $\mathrm{n}=21)$.

\begin{tabular}{|c|c|c|c|}
\hline Título do Artigo & Autores & Metodologia & Resultados principais \\
\hline $\begin{array}{l}\text { Autoconfiança, conhecimento e habilidade acerca } \\
\text { da ressuscitação cardiopulmonar de internos de } \\
\text { enfermagem }\end{array}$ & $\begin{array}{l}\text { Brandão, M. G. S. A.; } \\
\text { et al, } 2020 .\end{array}$ & Estudo descritivo. & $\begin{array}{l}\text { Os internos em emergências apresentaram média baixa na } \\
\text { autoconfiança. }\end{array}$ \\
\hline $\begin{array}{l}\text { Conhecimento, atitude e prática dos enfermeiros } \\
\text { da atenção primária em relação a parada } \\
\text { cardiorrespiratória }\end{array}$ & $\begin{array}{l}\text { Claudiano,M.S.;et } \\
\text { al,2020. }\end{array}$ & $\begin{array}{l}\text { Estudo de corte } \\
\text { transversal }\end{array}$ & $\begin{array}{l}\text { Dos } 29 \text { enfermeiros inseridos, } 87,5 \% \text { encontraram } \\
\text { dificuldades na RCP. }\end{array}$ \\
\hline $\begin{array}{l}\text { Ensino de ressuscitação cardiopulmonar por meio } \\
\text { de videoaula }\end{array}$ & $\begin{array}{l}\text { Martins, A. R.; et } \\
\text { al,2020. }\end{array}$ & Estudo descritivo. & $\begin{array}{l}\text { Dos entrevistados, } 51,6 \% \text { responderam corretamente o } \\
\text { questionário e após se capacitarem, houve } 59,3 \% \text { de } \\
\text { acerto. }\end{array}$ \\
\hline $\begin{array}{l}\text { Aprendizagem de estudantes de técnico em } \\
\text { enfermagem sobre as manobras de ressuscitação } \\
\text { cardiopulmonar em suporte básico de vida }\end{array}$ & $\begin{array}{l}\text { Benvenuti, C.; et } \\
\text { al,2020. }\end{array}$ & Estudo descritivo. & $\begin{array}{l}\text { Treinamento sobre o assunto se fez eficaz, principalmente } \\
\text { na instituição privada após teste tardio, apresentando os } \\
\text { estudantes maior número de acerto sobre a posição de } \\
\text { realização de RCP, }\end{array}$ \\
\hline $\begin{array}{l}\text { Conhecimento e atuação da equipe de } \\
\text { enfermagem de um setor de urgência no evento } \\
\text { parada cardiorrespiratória }\end{array}$ & $\begin{array}{l}\text { Moura, J. G. de; B.; } \\
\text { et al,2019. }\end{array}$ & Estudo descritivo. & $\begin{array}{l}\text { A maioria dos profissionais não sabe identificar } \\
\text { corretamente todos os sinais clínicos de uma PCR, sendo } \\
\text { na presente pesquisa a inconsciência o sinal clínico menos } \\
\text { assinalado. }\end{array}$ \\
\hline $\begin{array}{l}\text { Conhecimento da equipe de enfermagem sobre } \\
\text { ressuscitação cardiopulmonar }\end{array}$ & $\begin{array}{l}\text { Guskuma, E. M.; et } \\
\text { al,2019. }\end{array}$ & Estudo descritivo. & $\begin{array}{l}\text { Cerca de } 40,8 \% \text { souberam reconhecer a sequência de } \\
\text { atendimento da cadeia de sobrevida. }\end{array}$ \\
\hline
\end{tabular}




\begin{tabular}{|c|c|c|c|}
\hline $\begin{array}{l}\text { Parada e reanimação cardiorrespiratória: } \\
\text { conhecimento do enfermeiro baseado nas } \\
\text { diretrizes da American Heart Association } 2015\end{array}$ & $\begin{array}{l}\text { Barros, F. R. B. de; et } \\
a l, 2018 .\end{array}$ & Estudo descritivo. & $\begin{array}{l}\text { Apenas } 80 \% \text { dos pós-graduandos tinham conhecimento } \\
\text { para identificar uma parada cardiorrespiratória. }\end{array}$ \\
\hline $\begin{array}{l}\text { Impacto do treinamento sobre ressuscitação } \\
\text { cardiopulmonar em um ambulatório de } \\
\text { especialidades cardiológicas }\end{array}$ & $\begin{array}{l}\text { Paim, M. A. S.; et } \\
\text { al,2018. }\end{array}$ & $\begin{array}{l}\text { Relato de } \\
\text { experiência }\end{array}$ & $\begin{array}{l}\text { O treinamento em RCP possibilitou um maior } \\
\text { conhecimento da equipe, com número de acertos variando } \\
\text { de } 76,4 \% \text { a } 100 \% \text { após os testes. }\end{array}$ \\
\hline $\begin{array}{l}\text { O conhecimento do profissional de enfermagem } \\
\text { frente à parada cardiorrespiratória segundo as } \\
\text { novas diretrizes e suas atualizações }\end{array}$ & $\begin{array}{l}\text { Barbosa, I. S. L.; et } \\
\text { al,2018. }\end{array}$ & $\begin{array}{l}\text { Estudo } \\
\text { retrospectivo }\end{array}$ & $\begin{array}{l}\text { Cerca de } 83,33 \% \text { dos enfermeiros responderam que } \\
\text { usaram as novas } \\
\text { diretrizes de RCP } 2015 \text {. }\end{array}$ \\
\hline $\begin{array}{l}\text { Conhecimento teórico da enfermagem sobre } \\
\text { parada cardiorrespiratória e reanimação cardio } \\
\text { cerebral em unidade de terapia intensiva. }\end{array}$ & $\begin{array}{l}\text { Beccaria, L. M.; et } \\
\text { al,2017. }\end{array}$ & Estudo descritivo & $\begin{array}{l}\text { Cerca de } 66,96 \% \text { apresentaram conteúdo teórico } \\
\text { atualizado. }\end{array}$ \\
\hline $\begin{array}{l}\text { Avaliação do conhecimento dos enfermeiros } \\
\text { sobre os cuidados pós-parada cardiorrespiratória }\end{array}$ & $\begin{array}{l}\text { Lisboa, N. da S.; et } \\
\text { al,2016. }\end{array}$ & Estudo descritivo & $\begin{array}{l}\text { O melhor desempenho foi composto por enfermeiros que } \\
\text { participaram de cursos de atualização no último ano. }\end{array}$ \\
\hline $\begin{array}{l}\text { Conhecimento dos docentes e discentes de } \\
\text { enfermagem sobre o suporte básico de vida }\end{array}$ & $\begin{array}{l}\text { Medeiros, A. B. de; } \\
\text { et al.,2021. }\end{array}$ & Estudo descritivo & Sobre a RCP, 77,5\% identificam sinais clínicos. \\
\hline $\begin{array}{l}\text { Conhecimento dos acadêmicos de enfermagem } \\
\text { sobre suporte básico de vida }\end{array}$ & $\begin{array}{l}\text { Resende, R. T.; et } \\
\text { al,2019. }\end{array}$ & Estudo descritivo & $\begin{array}{l}\text { Cerca de } 32,46 \% \text { dos acadêmicos atingiram notas } \\
\text { superiores a } 70 \% \text { do questionário. }\end{array}$ \\
\hline $\begin{array}{l}\text { Conhecimento de acadêmicos de enfermagem } \\
\text { sobre a reanimação }\end{array}$ & $\begin{array}{l}\text { Moraes, C. L.; et } \\
\text { al,2017. }\end{array}$ & Estudo descritivo & $\begin{array}{l}\text { Cerca de } 33,3 \% \text { dos participantes têm formação em RCP } \\
\text { além da graduação. }\end{array}$ \\
\hline $\begin{array}{l}\text { Conhecimento dos enfermeiros sobre o novo } \\
\text { protocolo de ressuscitação cardiopulmonar }\end{array}$ & $\begin{array}{l}\text { Díaz, F. B. B. de S.; } \\
\text { et al,2017. }\end{array}$ & Estudo descritivo & $\begin{array}{l}\text { Cerca de } 63,2 \% \text { dos enfermeiros já realizaram capacitação } \\
\text { em RCP. }\end{array}$ \\
\hline $\begin{array}{l}\text { Validação de questionário para a avaliação do } \\
\text { conhecimento de docentes e discentes de } \\
\text { enfermagem sobre o suporte básico de vida }\end{array}$ & $\begin{array}{l}\text { Freire, I., I. L. S.; et } \\
\text { al,2017. }\end{array}$ & $\begin{array}{l}\text { Estudo } \\
\text { quantitativo }\end{array}$ & $\begin{array}{l}\text { Das questões avaliadas na primeira rodada, cinco } \\
\text { obtiveram um índice de validade perfeito. }\end{array}$ \\
\hline $\begin{array}{l}\text { Intervenção educativa sobre parada } \\
\text { cardiorrespiratória intra-hospitalar: conhecimento } \\
\text { dos profissionais de enfermagem de unidades } \\
\text { médico-cirúrgicas }\end{array}$ & $\begin{array}{l}\text { Santos, R. P. dos; et } \\
\text { al,2017. }\end{array}$ & $\begin{array}{l}\text { Estudo do tipo } \\
\text { quase } \\
\text { experimental }\end{array}$ & $\begin{array}{l}\text { Cerca de } 90 \% \text { dos enfermeiros atuaram na PCR na unidade } \\
\text { em que trabalham. }\end{array}$ \\
\hline $\begin{array}{l}\text { Parada cardiorrespiratória: conhecimento dos } \\
\text { profissionais de enfermagem em uma unidade de } \\
\text { terapia intensiva }\end{array}$ & $\begin{array}{l}\text { Espindola, M. C. M.; } \\
\text { et al, } 2017 \text {. }\end{array}$ & Estudo descritivo & $\begin{array}{l}\text { Cerca de } 66,67 \% \text { dos enfermeiros acertaram sobre a } \\
\text { detecção de uma PCR. }\end{array}$ \\
\hline $\begin{array}{l}\text { Conhecimento da equipe de enfermagem do setor } \\
\text { de hemodiálise sobre o atendimento a parada } \\
\text { cardiorrespiratória }\end{array}$ & $\begin{array}{l}\text { Santos,M.S.; et al, } \\
2017 .\end{array}$ & $\begin{array}{l}\text { Estudo } \\
\text { quantitativo }\end{array}$ & $\begin{array}{l}\text { Apenas } 20 \% \text { dos participantes apresentaram conhecimento } \\
\text { satisfatório. }\end{array}$ \\
\hline
\end{tabular}

Fonte: Autores (2021).

Com base no exposto no Quadro 2, foram encontrados 21 artigos, dos quais $38 \%$ (8) corresponde a artigos publicados no ano de 2017, $19 \%$ (4) publicados no ano de 2020,19\% (4) publicados no ano de $2019,14,2 \%$ (3) publicados no ano de 2018, 4,76 \% (1) publicados no ano de 2016 e 4,76 \% (1) publicados no ano de 2021.

Relativo a metodologia, foi observado predominância de estudos do tipo descritivo, correspondendo a 76, 2 \% (16), seguidos de estudos de corte transversal 4,76 \% (1), estudo do tipo quase experimental 4,76\% (1), estudo do tipo quantitativo $4,76 \%$ (1), estudo de relato de experiência 4,76 \% (1) e estudo retrospectivo 4,76 \% (1) em menor porcentagem.

A partir dos resultados obtidos, realizou-se a categorização dos estudos, a partir dos seus principais achados.

\section{Categoria 1: Importância da educação continuada.}

Para se garantir um cuidado eficiente, se faz necessário um treinamento capacitante para a equipe de saúde, o qual se dá através da educação continuada, em estudo realizado por Paim et al (2018), foi-se realizado um abordagem colaborativa com a equipe de saúde para realização de um plano de ação para realização do treinamento, garantindo oportunidade de fala e 
esclarecimento de dúvidas, o sucesso da prática foi observado através da realização de testes em dois momentos, antes do treinamento e após, sendo que após o treinamento houve um número maior de acertos pelos participantes (Paim et al., 2018).

Corroborando a importância de treinamento e educação continuada para um caso de PCR, encontra-se o estudo de Moura et al. (2019), o qual faz referência a importância de um treinamento adequado, visto que houve um baixo percentual de respostas corretas pelos profissionais sobre o tema.

O treinamento específico se faz importante não apenas em ambiente hospitalar, mas também em ambiente profissionalizante, contudo verifica-se que os scores de avaliação no período tardio mantiveram-se altos apenas nas instituições privadas. Verificou-se também o baixo conhecimento de manuseio do DEA (Desfibrilador Externo Automático), dado preocupante, pois o DEA atua como um facilitador do processo de RCP juntamente com as manobras de SBV, nota-se também um conhecimento baixo relativo à sequência correta de atendimento a PCR e ao uso de desfibrilador no pré-teste com $46,2 \%$ de acertos (Benvenuti et al., 2020).

Relativo ao uso do DEA, fortalece-se o que foi encontrado no estudo de Benvenuti et al. (2020), no estudo realizado por Martins et al. (2020), no qual antes da aplicação de treinamento 51,6\% dos participantes tinham conhecimento sobre seu uso e, após treinamento 59,3\% tinham conhecimento sobre RCP com uso do DEA.

Além do conhecimento sobre o uso dos equipamentos, nota-se que em estudo que 70,8\% dos profissionais não tinham conhecimento da técnica de elevar o membro durante e após administração via IV (Claudiano et al., 2020).

Contactua-se o exposto acima, com o observado em estudo de Santos et al. (2017), o qual aponta uma divergência de scores entre os profissionais nos pós e pré-teste, na via de administração de fármacos, sendo essa diferença mais significante entre técnicos e auxiliares (Santos et al.,2017).

\section{Categoria 2: Relação confiança e experiência}

A segurança apresentada por um profissional durante o atendimento de PCR está mais relacionada ao desfecho do atendimento do que aos anos de experiência em si (Martins et al., 2020).

A experiência é apresentada como um fator importante para o reconhecimento de uma PCR em diversos estudos, tal qual o realizado por Santos et al. (2017), entre enfermeiros do setor de hemodiálise, os quais apresentaram baixo conhecimento sobre RCP. Em contrapartida, verifica-se alto conhecimento teórico entre estudantes de Enfermagem e baixa habilidades práticas, estando, portanto, intrinsecamente relacionado a confiança na realização de manobras de RCP com a experiência teórico-prática (Santos et al., 2017).

Investigou-se que os melhores desempenhos foram em profissionais já formados em instituições públicas ou que já estiveram em contato anterior sobre o tema, seja por meio de cursos, uma pós-graduação ou experiências profissionais. Sendo assim, alguns estudos com graduandos mostram a eficácia do treinamento em manequins que conseguem reproduzir funções como sinais vitais, sons cardíacos e pulmonares, entre outros, garantindo aquisição de conhecimentos e desenvolvendo habilidades psicomotoras que irão influenciar na atuação profissional (Moraes et al., 2017).

O profissional de enfermagem deve ser o agente facilitador durante uma PCR, organizando o ambiente, provendo de recursos materiais, além de capacitar sua equipe para um bom atendimento à parada. Um dos seus pré-requisitos como rapidez, eficiência, conhecimento técnico-científico, habilidades técnicas são grandes fatores para diminuir riscos de sobrevida, mantendo assim a segurança do paciente (Beccaria et al., 2017).

O conhecimento da equipe de enfermagem em base as diretrizes, como por exemplo da AHA, são importantes para o sucesso no atendimento, visto que, na maioria dos casos, é a própria equipe que se depara com situações de PCR, dispondo de conhecimento teórico e prático a fim de realizar o atendimento com qualidade. Deve- se ser proporcionada educação para articular a teoria com a prática, indo ao encontro da necessidade de atualização devido a estes protocolos e suas mudanças. 
Essas atualizações ajudam na promoção de uma assistência segura e sistemática contribuindo para evitar mortes prematuras, iatrogenias, além de altas chances de sobrevida ao paciente (Diaz et al., 2017).

\section{Categoria 3: Consequência da falta de conhecimento}

Como principal consequência a falta de conhecimento, está o atraso em identificar uma PCR e garantir manobras de SBV em tempo oportuno para aumentar a sobrevida do paciente (Martins et al., 2020).

A identificação correta dos sinais clínicos mais comuns de uma PCR é indispensável para que haja sucesso na reanimação do paciente. $\mathrm{O}$ reconhecimento da ausência de resposta do paciente, respiração, pulso ou sinais de circulação são importantes para alertarem a necessidade de um suporte rápido e eficaz (Freire et al., 2017).

Outro fator importante a ser apontado, é o uso de diretrizes antigas, bem como não iniciar a RCP com manobras, dado que a compressão infere diretamente na sobrevida, bem como o reconhecimento precoce de uma PCR (Claudiano et al., 2020).

O não reconhecimento do ritmo de parada no monitor é um implicante direto a sobrevida, pela existência de ritmos chocáveis e não chocáveis, bem como a utilização correta de medicação e suas respectivas vias de administração, podem resultar em um desfecho positivo ou negativo da parada (Espíndola et al., 2017).

Segundo um estudo da Resende et al. (2019) cerca de 51,9\% dos participantes discordaram sobre a universidade fornecer conhecimentos teóricos e práticos para atendimento a uma PCR, onde classificaram suas aulas sobre PCR e RCP como insatisfatórias. Diante do estudo, os estudantes estão concluindo sua graduação com o mínimo de preparação para atuar frente uma vítima de parada cardiorrespiratória, comprometendo o paciente com possíveis sequelas ou até mesmo o óbito.

\section{Considerações Finais}

É imprescindível a constante atualização e pensamento crítico frente a área de urgência e emergência, na qual a PCR tem prevalência nos profissionais, principalmente os de enfermagem, devem se manter atentos e vigilantes diante dos principais sinais e sintomas de PCR, atentando-se para as orientações de órgãos internacionais e protocolos vigentes na instituição da qual faz parte a fim de evitar sequelas frente a uma má administração de tempo ou elencar erroneamente prioridades, visto que o tempo é um fator crucial nesse tipo de situação clínica.

Dentre os principais fatores que predispõe a um desfecho negativo e com possíveis sequelas estão a utilização incorreta de medicações e o reconhecimento do ritmo de parada, destaca-se aqui a importância de ler diretrizes e/ou guias práticos atualizados, pois se trata de estudos qualitativos e quantitativos que analisam as ações e suas consequências em uma gama considerável de pacientes a fim de verificar quais intervenções são realmente necessárias.

Nesse sentido, nota-se um maior preparo a longo prazo de profissionais formados a partir de instituições de ensino superior particulares, entretanto salienta-se que deve garantir integração entre a prática e teoria, pois conforme visto os profissionais estão se formando com grande insatisfação dos seus conhecimentos sobre PCR, afetando diretamente na sua atuação frente a mesma.

Portanto, para suprir essa necessidade, uma vez que inseridos dentro do mercado de trabalho esses profissionais devem passar por educação continuada sobre o tema, atualizando seus conhecimentos e intercalando prática com teoria, garantindo segurança para realização de intervenções.

Os autores salientam a importância de maiores estudos sobre o tema, dada a sua relevância e implicações para a Enfermagem. Tais estudos deveriam abordar sobre como a inexperiência e a falta de conhecimento podem afetar a saúde do paciente durante uma PCR. 


\section{Referências}

Brandão, M. G. S. A., Fontenele, N. A. O., Ximenes, M. A. M., Lima, M. M. S., Galindo Neto, N. M., Araújo, T. M., \& Barros, L. M. (2020). Autoconfiança, conhecimento e habilidade acerca da ressuscitação cardiopulmonar de internos de enfermagem. Revista Cuidarte, 11(2), e982.

Medeiros, A. B., Freire, I. L. S., Santos, F. R., Silva, B. C. O., Batista, G. F. M., \& Menezes, M. M. (2021). Conhecimento dos docentes e discentes de enfermagem sobre o suporte básico de vida. Rev. enferm. atenção saúde, 10, e-202102.

Velasco, I. T. (2019). Suporte avançado de vida. In: Brandão Neto, R. A., Souza, H. P., Marino, L. O., Marchini, J. F. M., \& Alencar, J. C. G. (Org). Medicina de emergência: abordagem prática, 14. ed, São Paulo: Manole.

Guskuma, E. M., Lopes, M. C. B. T., Piacezzi, L. H. V., Okuno, M. F. P., Batista, R. E. A., \& Campanharo. C. R. V. (2019). Nursing team knowledge on cardiopulmonary resuscitation. Rev. eletrônica enferm, 21, 1-8.

Barbosa, I. S.L., Moraes Filho, I. M., Pereira, B. A., Soares, S. R., Silva, W., \& Santos, O. P. (2018). O conhecimento do profissional de enfermagem frente à parada cardiorrespiratória segundo as novas diretrizes e suas atualizações. Revista de Divulgação Científica Sena Aires, 7(2),117-126.

Lisboa, N. S., Borges, M. S., \& Monteiro, P. S. (2016). Avaliação do conhecimento dos enfermeiros sobre os cuidados pós-parada cardiorrespiratória. Rev. enferm. UFPE on line, 10(10), 3778-3786.

Barros,F. R. B.,\& Neto, M.L. (2018). Parada e reanimação cardiorrespiratória: conhecimento do enfermeiro baseado nas diretrizes da American Heart Association 2015. Enfermagem em foco, 9(3), 8-12.

Ramalho Neto, J. M., Marques, D. K. A., Fernandes, M. G. M., \& Nóbrega, M. M. L. (2016). Análise de teorias de enfermagem de Meleis: revisão integrativa. Rev. Bras. Enferm, 69(1), 162-168.

Ercole, F. F., Melo, L. S., Alcoforado, C. L. G. C. (2014). Revisão integrativa versus revisão sistemática. Rev Min Enferm,18(1), 1-260.

Santos, M. A. R. C., \& Galvão, M. G. A. (2014). A elaboração da pergunta adequada de pesquisa. Resid Pediatr, 4(2), 53-56.

Paim, M. A. S., Luz, V. B. S., \& Simonetti, S. H. (2018). Impacto do treinamento sobre ressuscitação cardiopulmonar em um ambulatório de especialidades cardiológicas. Arq. bras. cardiol, 111(3 supl.1),164-164.

Moura, J. G., Brito, M. D. P. S., Rocha, G. D. O. S., \& Moura, L. T. R. (2019). Conhecimento e Atuação da Equipe de Enfermagem de um Setor de Urgência no Evento Parada Cardiorrespiratória. Revista de Pesquisa Cuidado é Fundamental Online, 11(3), 634-640.

Benvenuti, C., Beccaria, L. M., Barbosa, T. P., Rodrigues, C. D. S., \& Jacon, J. C. (2020). Aprendizagem de estudantes de técnico em enfermagem sobre as manobras de ressuscitação cardiopulmonar em suporte básico de vida. CuidArte, Enferm, 81-87.

Martins, A. R., Silva, M. L., Carvalho, M. T. M., \& Garcia, J.S. (2020). Ensino de ressuscitação cardiopulmonar por meio de videoaula. J Nurs UFPE on line, $14, \mathrm{e} 243145$.

Claudiano, M. D. S., Lopes, N. N. L., Santos, M. V. F. D., Lopes, A. B., \& Fiorin, B. H. (2020). Conhecimento, atitude e prática dos enfermeiros da atenção primária em relação a parada cardiorrespiratória. Nursing (Säo Paulo), 3502-3506.

Santos, M. S., Toledo, L. V., Alves, K. R., Santana, M. M. R., Ribeiro, L., \& Diaz, F. B. B. S. (2017). Conhecimento da equipe de enfermagem do setor de hemodiálise sobre o atendimento a parada cardiorrespiratória. HU Revista, 43(4), 375-381.

Santos, R. P., Hofstatter, L. M., Carvalho, A. R. S., \& Alves, S. R. (2017). Intervenção educativa sobre parada cardiorrespiratória intra-hospitalar: conhecimento dos profissionais de enfermagem de unidades médico-cirúrgicas. Revista Eletrônica de Enfermagem, 19.

Moraes, C. L., Vasconcelos, P. R., Souza, E. A., Bellaguarda, M. L. R. (2017) Cardiopulmonar knowledge of nursing academics on cardiopulmonary rehability. Rev. enferm. Cent.-Oeste Min, 7,1-9.

Beccaria, L. M., Santos, K. F., Trombeta, J.C., Rodrigues, A. M. S., Barbosa, T. P., Jacon, J. C. (2017) Conhecimento teórico da enfermagem sobre parada cardiorrespiratória e reanimação cardiocerebral em unidade de terapia intensiva theoretical nursing. CuidArte, Enferm., 11(1), 51-58.

Diaz, F. B. B. D. S., Novais, M. E. F., Alves, K. R., Cortes, L. P., \& Moreira, T. R. (2017). Conhecimento dos enfermeiros sobre o novo protocolo de ressuscitação cardiopulmonar. Rev. enferm. Cent.-Oeste Min, 1-8.

Freire, I. L. S., Santos, F. R., Nascimento, A. C. S., Medeiros, A. B., Silva, B. C. O., \& Cavalcante, C. A. A. (2017). Validação de questionário para a avaliação do conhecimento de docentes e discentes de enfermagem sobre o suporte básico de vida. Revista de Enfermagem UFPE on line, 11(12), 4953-4960.

Espindola, M. C. M., Espíndola, M. M. M., Moura, L. T. R., \& Lacerda, L. C. A. (2017). Parada cardiorrespiratória: conhecimento dos profissionais de enfermagem em uma unidade de terapia intensiva. Revista de enfermagem UFPE on line, 11(7), 2773-2778.

Resende, R. T., Barbosa, A. C. S., Luiz, F. S., Santos, K. B. D., Frank, D. B. P., Motta, D. D. S., Tony, A. C. C., \& Carbogim, F. D. C. (2019). Conhecimento dos acadêmicos de enfermagem sobre suporte básico de vida. Rev. enferm. UFPE on line, 1231-1236. 